\title{
Temporal Behavior of Stratospheric Ammonia Abundance and Temperature Following the SL9 Impacts
}

\author{
Kelly Fast, ${ }^{1}$ Theodor Kostiuk, Paul Romani, and Fred Espenak \\ Planetary Systems Branch, Laboratory for Extraterrestrial Physics, NASA Goddard Space Flight Center, Greenbelt, Maryland 20771 \\ E-mail: Kelly.Fast@gsfc.nasa.gov \\ Tilak Hewagama ${ }^{2}$ \\ Department of Astronomy, University of Maryland, College Park, Maryland 20742-2421
}

Albert Betz and Rita Boreiko

CASA, University of Colorado, 593 UCB, Boulder, Colorado 80303

and

Timothy Livengood ${ }^{2}$

Challenger Center for Space Science Education, 1029 North Royal Street, Suite 300, Alexandria, Virginia 22314

Received March 13, 2001; revised September 4, 2001

Infrared emission lines of stratospheric ammonia $\left(\mathrm{NH}_{3}\right)$ were observed following the collisions of the fragments of Comet Shoemaker-Levy 9 with Jupiter in July of 1994 at the impact sites of fragments G and K. Infrared heterodyne spectra near $10.7 \mu \mathrm{m}$ were obtained by A. Betz et al. (in Abstracts for Special Sessions on Comet Shoemaker-Levy 9, The 26th Meeting of the Division for Planetary Sciences, Washington DC, 31 Oct.-4 Nov. 1994, p. 25) using one of the Infrared Spatial Interferometer telescope systems on Mount Wilson. Lineshapes of up to three different $\mathrm{NH}_{3}$ emission lines were measured at a resolving power of $\sim 10^{7}$ at multiple times following the impacts. We present here our radiative transfer analysis of the fully resolved spectral lineshapes of the multiple rovibrational lines. This analysis provides information on temperature structure and $\mathrm{NH}_{3}$ abundance distributions and their temporal changes up to 18 days after impact. These results are compared to photochemical models to determine the role of photochemistry and other mechanisms in the destruction and dilution of $\mathrm{NH}_{3}$ in the jovian stratosphere after the SL9 impacts.

One day following the $\mathrm{G}$ impact, the inferred temperature above 0.001 mbar altitude is $283 \pm 13 \mathrm{~K}$, consistent with a recent plume splashback model. Cooling of the upper stratosphere to $204 \mathrm{~K}$ by the fourth day and to quiescence after a week is consistent with a simple gray atmosphere radiative flux calculation and mixing

\footnotetext{
${ }^{1}$ Formerly at Department of Astronomy, University of Maryland, College Park, MD 20742-2421.

${ }^{2}$ Also at Planetary Systems Branch, Laboratory for Extraterrestrial Physics, NASA Goddard Space Flight Center, Greenbelt, MD 20771.
}

with cold jovian air. During the first 4 days after impact, $\mathrm{NH}_{3}$ was present primarily at altitudes above 1 mbar with a column density of $(7.7 \pm 1.6) \times 10^{17} \mathrm{~cm}^{-2}$ after 1 day and $(3.7 \pm 0.8) \times 10^{17} \mathrm{~cm}^{-2}$ after 4 days. (Errors represent precision.) We obtained $>2.5$ times more $\mathrm{NH}_{3}$ than can be supplied by nitrogen from a large cometary fragment, suggesting a primarily jovian source for the $\mathrm{NH}_{3}$. By 18 days postimpact, a return to quiescent upper stratospheric temperature is retrieved for the $\mathrm{G}$ region, with an $\mathrm{NH}_{3}$ column density of $7.3 \times 10^{17} \mathrm{~cm}^{-2}$ or more in the lower stratosphere, possibly supplied by $\mathrm{NH}_{3}$ upwelling across an impact-heated and turbulent tropopause, which may have been masked by initial dust and haze. Above the 1-mbar level, the maximum retrieved column density decreased to $6.5 \times 10^{16} \mathrm{~cm}^{-2}$. Comparison to photochemical models indicates that photolysis alone is not sufficient to account for the loss of $\mathrm{NH}_{3}$ above 1 mbar by that time, even when chemical reformation of $\mathrm{NH}_{3}$ is ignored. We speculate that the dispersion of plume material at high altitudes (above $1 \mathrm{mbar}$ ) is responsible for the change in the spectra observed a few days postimpact. Data on the K impact region provide qualitatively consistent results. (c) 2002 Elsevier Science (USA)

Key Words: Comets S-L9; Jupiter; Jupiter-atmosphere; infrared observations; photochemistry.

\section{INTRODUCTION}

The collision of comet Shoemaker-Levy 9 with Jupiter in July of 1994 provided a unique opportunity to investigate not only planetary impacts but also jovian composition, photochemistry, and thermal rebound. Knowledge of the time scales for 
TABLE I

Molecular Line Parameters

\begin{tabular}{cccr}
\hline $\mathrm{NH}_{3}$ transition & $\begin{array}{c}\text { Frequency } \\
\left(\mathrm{cm}^{-1}\right)\end{array}$ & $\begin{array}{c}\text { Lower state } \\
\text { energy }\left(\mathrm{cm}^{-1}\right)\end{array}$ & $\begin{array}{c}\text { Intensity }^{a} \\
\left(\mathrm{~cm}^{-2} \mathrm{~atm}^{-1}\right)\end{array}$ \\
\hline $\mathrm{aQ}(2,2)$ & 931.3332 & 45.6 & 5.43 \\
$\mathrm{aQ}(6,6)$ & 927.3229 & 284.4 & 11.18 \\
$\mathrm{aQ}(9,8)$ & 926.0457 & 656.4 & 1.08 \\
\hline
\end{tabular}

Source. HITRAN, Rothman et al. 1992.

${ }^{a}$ Intensities at $296 \mathrm{~K}$, later scaled to model temperature.

the cooling of the atmosphere back to a quiescent state and the destruction of deposited species not normally found in the stratosphere would help to better understand the impacts themselves and provide a test for jovian photochemical models. Ammonia $\left(\mathrm{NH}_{3}\right)$, which was injected into the stratosphere by the SL9 impacts, is an effective probe of its photochemistry as well as the stratospheric thermal structure following the collisions. Here we report results of retrievals from a unique set of measurements taken up to 18 days after impact, at a spectral resolution that can fully resolve the shapes of narrow stratospheric $\mathrm{NH}_{3}$ emission lines.

Infrared heterodyne spectroscopy with a resolving power of $\sim 10^{7}$ permits measurement of the true line profiles, revealing information about the temperature, abundance, and altitude distribution of the source species in the region of line formation. The portion of the data set acquired by Betz et al. (1994) that is examined in this paper provides important temporal information. The spectra were acquired on three occasions over an 18-day period following the impacts in the $\mathrm{G}$ region (Fig. 1). Multiple observations of the $\mathrm{K}$ region were also made (Fig. 2), following the nearby smaller impact of fragment $\mathrm{W}$. The current measurements include emission profiles of several $\mathrm{NH}_{3}$ transitions, each of different line intensity and lower state energy (Table I).
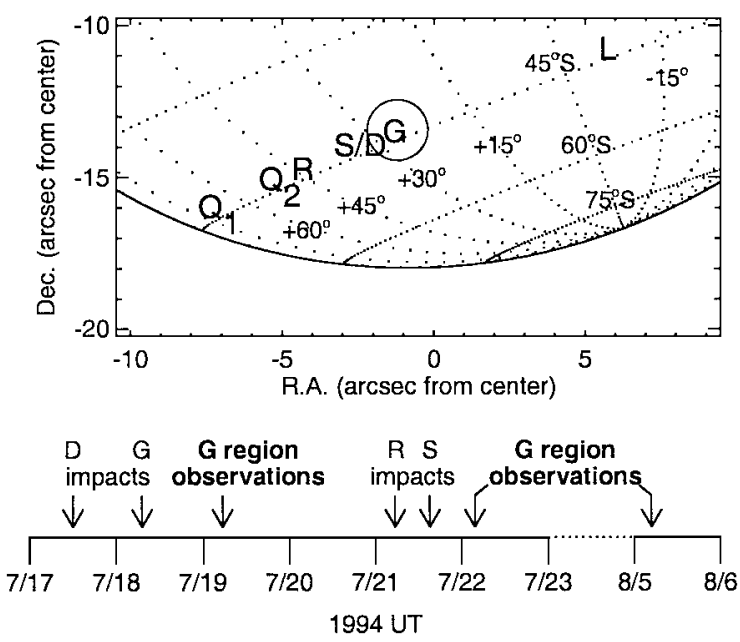

FIG. 1. Jupiter aspect geometry showing impact latitude and the instrumental field-of-view of 2 arcsec. The timeline shows the $\mathrm{G}$ region observation times relative to the different impact times.
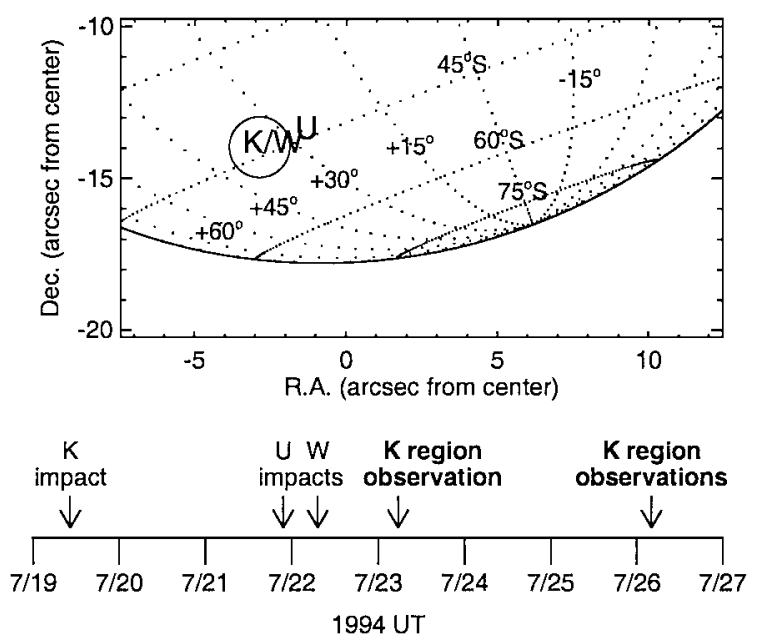

FIG. 2. K region observation timeline. All $\mathrm{K}$ region observations were made after the impacts that affected that region had ceased.

The different line intensities and the different dependence of each line emission on temperature provided a significant constraint on the temperature and the altitude distribution of $\mathrm{NH}_{3}$ abundance in the emitting region. This is an improvement over a similar analysis of infrared heterodyne spectra from impacts Q1 and R (Kostiuk et al. 1996) that retrieved information on $\mathrm{NH}_{3}$ altitude distribution and abundance based on a single line measured about a week after each impact.

We used a beam-integrated radiative transfer analysis developed by Goldstein (1989) and Hewagama et al. (in preparation), and retrieved temporal changes in $\mathrm{NH}_{3}$ abundance and stratospheric temperature and their altitude distributions on Jupiter. We test new photochemical models, which include photochemical destruction and recycling of $\mathrm{NH}_{3}$ due to the effects of a changing atmospheric temperature over the observing period.

\section{OBSERVATIONS AND ANALYSIS}

\section{Data Acquisition and Reduction}

The spectra were obtained using an infrared heterodyne system (Betz et al. 1977) on one of the 1.65-m telescopes of the Infrared Spatial Interferometer (ISI; Hale et al. 2000) at Mount Wilson, California. The infrared heterodyne technique and its application to planetary atmospheres are described by Kostiuk (1994) and Kostiuk et al. (1997) in application to planetary atmospheres. Isolated emission lines of $\mathrm{NH}_{3}$ near $10.7 \mu \mathrm{m}$ were measured at a spectral resolution of $\sim 3.2 \mathrm{MHz}\left(\Delta \nu_{\lambda}=10^{-4} \mathrm{~cm}^{-1}\right.$, $\left.v_{\lambda} / \Delta v_{\lambda} \sim 10^{7}\right)$. Integration times varied from 8 to 40 min over the observing period. The three lines of $\mathrm{NH}_{3}$ that were measured and their molecular parameters (frequency, intensity, and lower state energy at $296 \mathrm{~K}$ ) are summarized in Table I. The observations were made by actively tracking on an impact region. In the weeks following the impacts, tracking errors were large due to the lack of clear features to track on. This error can 
TABLE II

Observation Summary

\begin{tabular}{cccccc}
\hline $\begin{array}{c}\text { Impact } \\
\text { region }\end{array}$ & $\begin{array}{c}\text { UT Date } \\
1994\end{array}$ & $\begin{array}{c}\text { Days after } \\
\text { impact }\end{array}$ & aQ(2,2) & aQ(6,6) & aQ(9,8) \\
\hline G & Jul 19 & 1 & $\checkmark$ & $\checkmark$ & \\
G & Jul 22 & 4 & $\checkmark$ & $\checkmark$ & $\checkmark$ \\
G & Aug 5 & 18 & $\checkmark$ & & \\
K & Jul 23 & 4 & $\checkmark$ & & \\
K & Jul 26 & 7 & $\checkmark$ & $\checkmark$ & \\
\hline
\end{tabular}

be determined from individual scans and is taken into account in the analysis. Different transitions of $\mathrm{NH}_{3}$ were measured at multiple impact sites on a given day. This work focuses on spectra obtained at the $\mathrm{G}$ and $\mathrm{K}$ impact regions following the impacts (Table II). Absolute spectral radiances were obtained using a lunar calibration, with conservative uncertainties of $\sim 10 \%$.

\section{General Analysis}

In our analysis, the measured $3.2-\mathrm{MHz}$ resolution was degraded to $\sim 8-\mathrm{MHz}$ resolution $\left(0.0003 \mathrm{~cm}^{-1}\right)$, more than adequate for resolving emission lineshapes of $\sim 200 \mathrm{MHz}$ full width at half maximum (FWHM). The effective field-of-view (FOV) for analysis, including instrumental beam size and atmospheric seeing, is 2 arcsec diameter, $\sim 8000 \mathrm{~km}$ projected onto Jupiter. The plume splashback region for the $\mathrm{G}$ and $\mathrm{K}$ impacts is $\geq 10,000 \mathrm{~km}$ (Hammel et al. 1995, Jessup et al. 2000, Bézard et al. 1997), filling the FOV. Spectra were analyzed by comparison with models of the emergent molecular lines produced by our radiative transfer software package, BEAMINT (Hewagama et al., in preparation). The beam-integration technique involves dividing the beam aperture into multiple sections and producing a model spectrum for specified physical conditions such as temperature, abundance, planetary rotation, and mean viewing angle within each section of the beam. The broadening due to planetary rotation $(\sim 150 \mathrm{MHz})$ is modeled by the software. The beam elements are combined, with beam element area and beam response weighting, to produce a beam-integrated spectrum. Since a single beam covers a relatively broad range of viewing angles on Jupiter, BEAMINT provides a more accurate characterization of an observed spectrum than a single-point mean viewing angle spectral model. This proved to be especially useful in the case of a spectrum with a large but known tracking error. We were able to recreate the larger broadening due to planetary rotation across a wider beam profile through the use of multiple multielement beams.

The radiative transfer portion of the program accepts molecular line parameters (Table I), arbitrary temperature and molecular mole fraction profiles, and planetary parameters. The radiative transfer calculation scales the molecular line intensities to the kinetic temperature corresponding to the region of line formation. The hydrogen broadened half width at half maximum (HWHM) for $\mathrm{NH}_{3}$ used is $0.115 \mathrm{~cm}^{-1} \mathrm{~atm}^{-1}$ at $200 \mathrm{~K}$ (Margolis and
Poynter 1991), and the pressure-broadening temperature dependence is $T^{-0.5}$.

In our analysis, we investigated the variation of the beamintegrated spectrum, which results from changing the abundance and temperature distribution. Generally, the change in the spectrum is nonlinear; therefore we used a modified LevenbergMarquardt algorithm to perform the least-squares fit of the model spectrum to the observations. Specifically, we used constantwith-height $\mathrm{NH}_{3}$ mole fraction distributions over various altitude ranges (e.g., 150 to 1 mbar, 1-mbar level and higher). The range in the altitude of this constant-with-height distribution is selected as warranted by the lineshape. In most cases, the $\mathrm{NH}_{3}$ mole fraction and temperature profile optimization were performed simultaneously using the Levenberg-Marquardt fitting technique. The errors are based on the joint probability distribution for the fit parameters and allow us to place conservative limits on the possible temperatures and amounts of $\mathrm{NH}_{3}$ present in the stratosphere at different times following an impact. The quoted uncertainties give $68.3 \%$ confidence limits (i.e., $1 \sigma$ ) for a particular thermal profile and $\mathrm{NH}_{3}$ mole fraction distribution.

\section{Thermal Analysis}

The initial thermal profile for the analysis is a quiescent jovian Voyager thermal profile roughly corresponding to the impact latitude (Fig. 3, profile $a$; Kostiuk et al. 1987). For each observing period, the profile was modified in the upper stratosphere in an attempt to fit our measurements on all emission lines

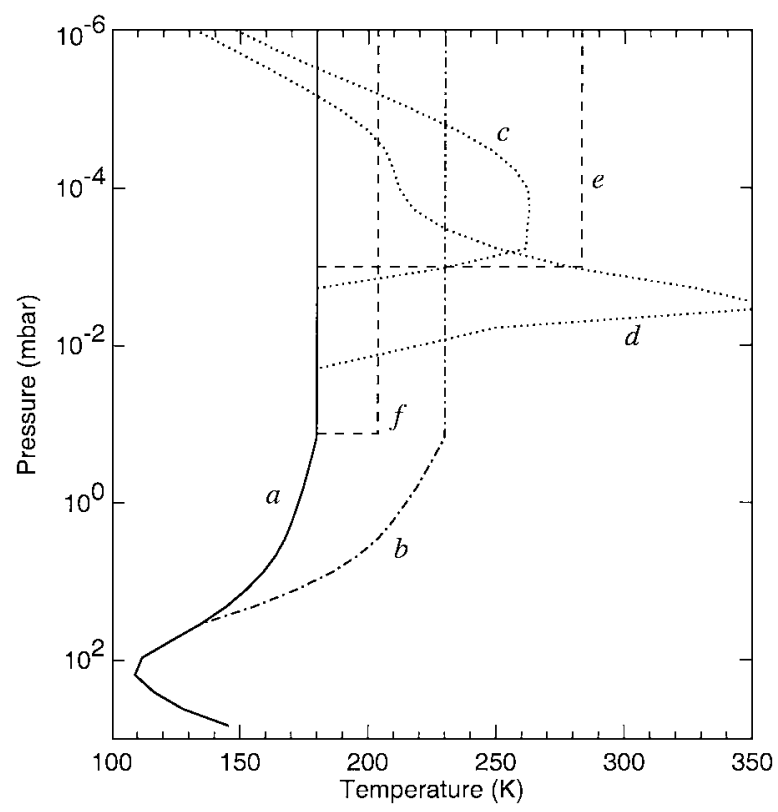

FIG. 3. Temperature profiles used for modeling. A quiescent Voyager profile (a) was used as a starting point. A uniform method of heating this profile (b) was found to be inadequate for the period soon after impact. Plume splashback temperature profiles $(c, d)$ were used as guides to develop temperature profiles $(e, f)$ that could simultaneously fit all $\mathrm{NH}_{3}$ lines measured in the days following impact $\mathrm{G}$ 
simultaneously. Initial analyses uniformly modified (heated) the profile down to higher pressures (e.g., Fig. 3, profile $b$ ). This approach did not provide adequate fits to all measured lines for any attempted $\mathrm{NH}_{3}$ altitude distribution.

Recently, a ballistic Monte Carlo and radiative-hydrodynamic treatment of the splashback process has been able to account for many SL9 phenomena, including several previously unexplained aspects (Harrington and Deming 2001, Deming and Harrington 2001 (hereafter HD-DH)). The splashback shocks for large impacts like $\mathrm{G}$ and $\mathrm{K}$ heat the atmosphere above approximately $0.01 \mathrm{mbar}$. Examples of residual heating from the HD-DH model are shown in Fig. 3, profiles $c$ and $d$. Differences in the modeled profiles result from radial variations in the plume column density and from waves and turbulence following the splashback.

We used the HD-DH result of high-altitude heating due to the plume splashback as a guide for our thermal analysis. We modified the quiescent Voyager thermal profile above the 0.01-mbar level as well as above other high altitude levels, as opposed to our earlier uniform heating of the profile down to lower stratospheric altitudes. There was a great improvement in the ability to simultaneously model all line profiles from a particular observing day. The heating altitude, the temperature, and the $\mathrm{NH}_{3}$ abundance and altitude distribution were simultaneously iterated until a best fit to all line profiles was achieved.

\section{G Impact Region}

$G$ impact plus 1 day. The $\mathrm{aQ}(2,2)$ and $\mathrm{aQ}(6,6) \mathrm{NH}_{3}$ emission lines (Table I) were acquired from the $\mathrm{G}$ impact region $22 \mathrm{~h}$ after impact (Fig. 4). The two molecular lines were modeled simultaneously, using constant-with-height $\mathrm{NH}_{3}$ mole fraction distributions with various lower altitude cutoffs, from $150 \mathrm{mbar}$ (tropopause) to 0.3 mbar. As previously mentioned, thermal profiles based on uniform heating of a quiescent Voyager temperature profile above 35 mbar (e.g., Fig. 3, profile $b$ ) did not yield adequate fits to both lines simultaneously. Because the HD-DH plume splashback model indicated high-altitude heating, we tried heating the thermal profile above various high altitude levels. This resulted in adequate simultaneous fits to both lines.

Ranges in both $\mathrm{NH}_{3}$ distribution cutoff altitudes and altitudes for heating the thermal profile were tested. Results indicate that $\mathrm{NH}_{3}$ was primarily observed at altitudes above $\sim 3$ mbar. The best fit to the spectra places the observed $\mathrm{NH}_{3}$ above the 1-mbar level (solid-line fit in Fig. 4). The resulting $\mathrm{NH}_{3}$ mole fraction above the 1-mbar level was $(6.8 \pm 1.4) \times 10^{-6}$, and the column density was $(7.7 \pm 1.6) \times 10^{17} \mathrm{~cm}^{-2}$. The best temperature profile was found by heating the quiescent profile above $0.001 \mathrm{mbar}$ to $283 \pm 13 \mathrm{~K}$. The calibrated measured line brightness temperatures $(>190 \mathrm{~K})$ require significant heating at high altitudes where the line peaks are formed. The lineshapes also require contributions around the 1-mbar level to properly model the line wings. The heating can acceptably extend as low as the 0.003-mbar level, resulting in a comparable column density but requiring a lower temperature $(240 \mathrm{~K})$. The $\mathrm{NH}_{3}$ can extend as low as the 3-mbar level with a poorer model fit to the line peaks, but it would allow a temperature of $255 \mathrm{~K}$ down to the 0.01-mbar level and result in about half the column density of the best-fit model. Extending the heating below $\sim 0.01$ mbar causes the peak of the aQ $(2,2)$ model line to approach the intensity of the $\mathrm{aQ}(6,6)$ line, which is not seen in the data (Fig. 4,
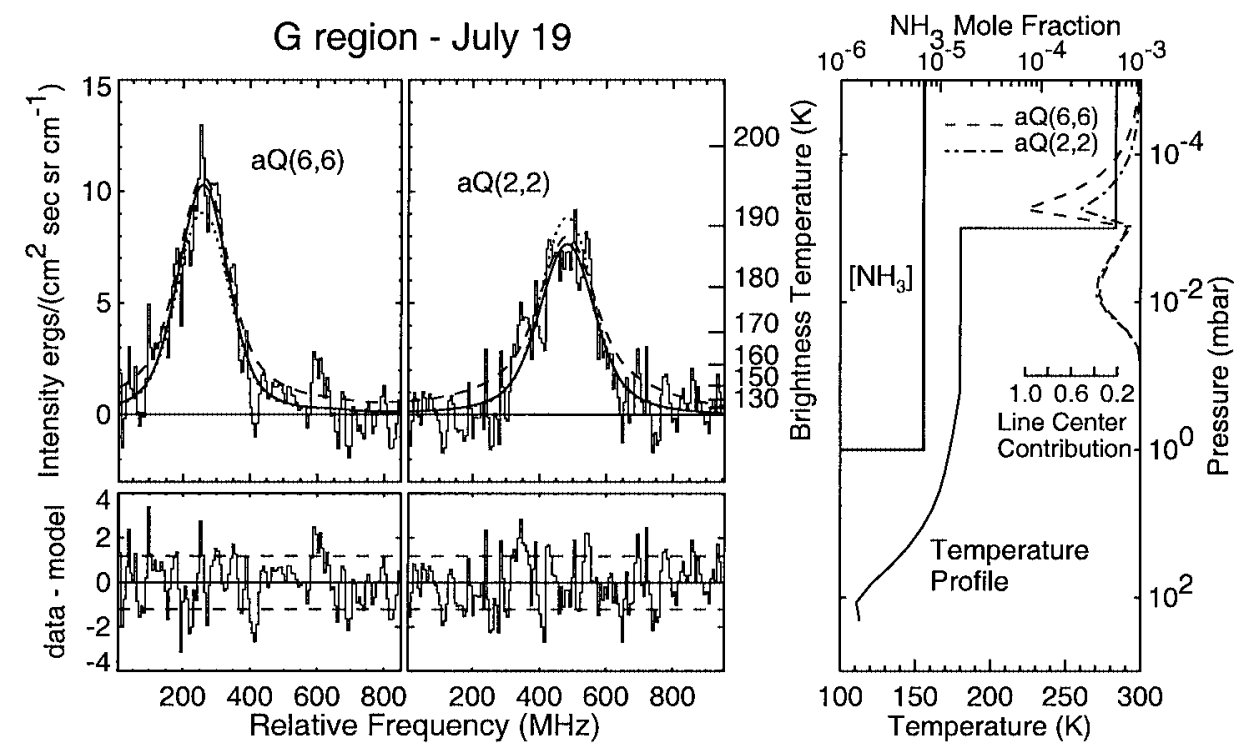

FIG. 4. G impact region spectra from July 19, 1994 ( $22 \mathrm{~h}$ after $\mathrm{G}$ impact). The model fit retrieved an $\mathrm{NH}_{3}$ mole fraction of $(6.8 \pm 1.4) \times 10^{-6}$ above the 1 -mbar level (column density $(7.7 \pm 1.6) \times 10^{17} \mathrm{~cm}^{-2}$ ) and an increase in temperature above quiescence to $283 \pm 13 \mathrm{~K}$ above the $10^{-3}$-mbar level. The dashed model indicates the inclusion below the 1 -mbar level of the retrieved $\mathrm{NH}_{3}$ mole fraction found 18 days after impact $\left(1.3 \times 10^{-7}\right)$ and is not an acceptable model. The dotted model illustrates how the fit to the line peaks degrades when the heating of the thermal profile extends below the $0.01-\mathrm{mbar}$ level $\left(\mathrm{NH}_{3}\right.$ mole fraction of $6.0 \times 10^{-6}$ down to 1 mbar, with heating above 0.03 mbar to $201 \mathrm{~K}$ ). 

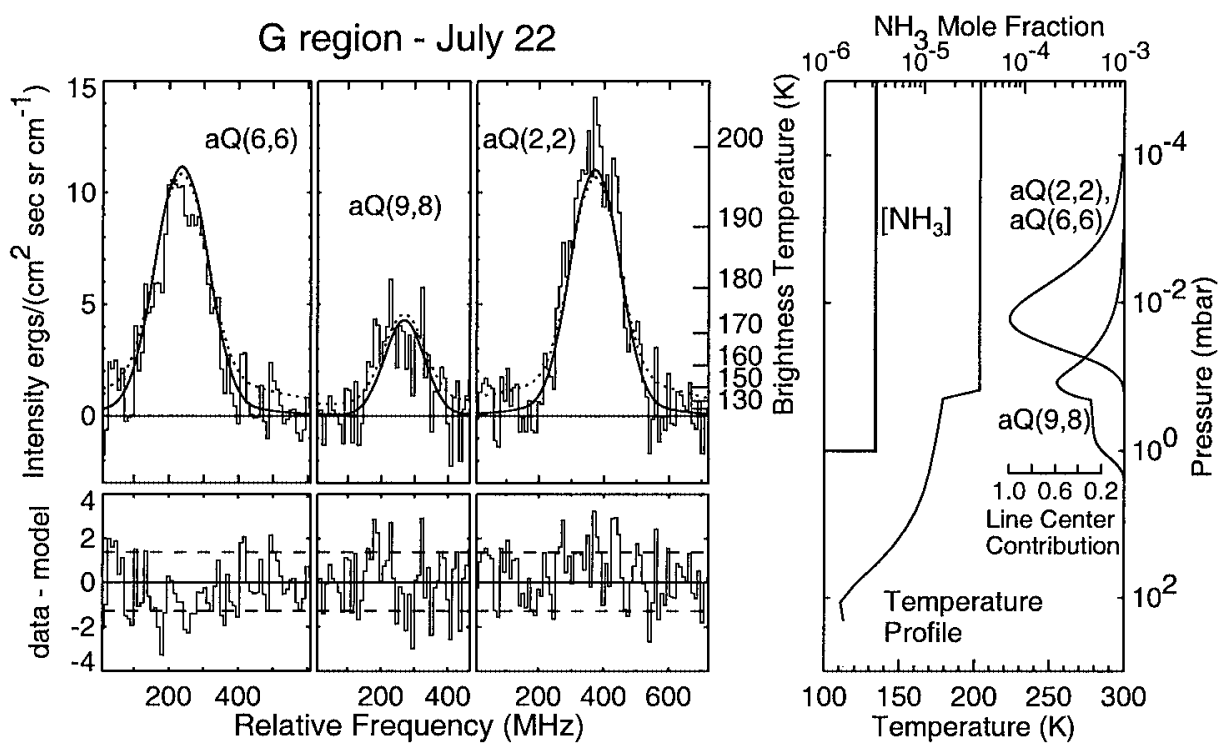

FIG. 5. G impact region spectra from July 22, 1994 (4 days after $\mathrm{G}$ impact). The best simultaneous fit to all three lines required an $\mathrm{NH}_{3}$ mole fraction of $(3.2 \pm 0.7) \times 10^{-6}$ above 1 mbar (column density $(3.7 \pm 0.8) \times 10^{17} \mathrm{~cm}^{-2}$ ) and the quiescent temperature profile heated to $204 \pm 1 \mathrm{~K}$ above $0.2 \mathrm{mbar}$. The relative line center contribution functions illustrate the advantage of using lines of different lower state energies to probe different regions of the atmosphere. The contribution from the $\mathrm{aQ}(9,8)$ line comes from an altitude region lower than that of the $\mathrm{aQ}(2,2)$ and aQ(6,6) lines, which helps to limit the range of possible temperature and $\mathrm{NH}_{3}$ mole fraction combinations that fit all three lines simultaneously. The dotted model illustrates how the wing fits degrade when $\mathrm{NH}_{3}$ is included below the 3-mbar level $\left(\mathrm{NH}_{3}\right.$ mole fraction of $3.7 \times 10^{-6}$ down to $10 \mathrm{mbar}$, with heating above $1 \mathrm{mbar}$ to $\left.205 \mathrm{~K}\right)$.

dotted model). Including $\mathrm{NH}_{3}$ at altitudes lower than $\sim 3$ mbar results in excess wing contribution.

$G$ impact plus 4 days. This was the one occasion on which all three different $\mathrm{NH}_{3}$ emission lines, $\mathrm{aQ}(2,2)$, aQ $(6,6)$, and $\mathrm{aQ}(9,8)$ (Table I), were observed on the same day within the $\mathrm{G}$ impact region. The $\mathrm{aQ}(2,2)$ and $\mathrm{aQ}(6,6)$ lines are strong lines of relatively low lower-state energies. The aQ $(9,8)$ line is a weaker line of higher lower-state energy that probes deeper in the atmosphere, and its higher temperature sensitivity provides a tighter constraint on the thermal structure.

Our initial models that involved heating the atmosphere down to a higher pressure (e.g., Fig. 3, profile $b$ ) were able to fit the line shape of the stronger aQ $(2,2)$ and $\mathrm{aQ}(6,6)$ lines but did not fit the $\mathrm{aQ}(9,8)$ line. When the model quiescent temperature profile was heated above higher altitudes, all three $\mathrm{NH}_{3}$ emission lines could be fit simultaneously (Fig. 5). The requirement that all three lines be modeled simultaneously places limits on the possible thermal and $\mathrm{NH}_{3}$ distributions that provide acceptable models. Measured line peak brightness temperatures again require significant heating at high altitudes $(\sim 0.1$-mbar level). The $\mathrm{aQ}(9,8)$ line probes lower and constrains the abundance and temperature in its emitting region (Fig. 5, contribution functions). It was found that an $\mathrm{NH}_{3}$ distribution only at altitudes above the 1-mbar level provided the best fit, with a mole fraction of $(3.2 \pm 0.7) \times 10^{-6}$ and a column density of $(3.7 \pm 0.8) \times 10^{17} \mathrm{~cm}^{-2}$. The retrieved temperature profile was cooler $(204 \pm 1 \mathrm{~K})$ than that found from the 1-day spectra, but the heating extended down to higher pressure $(0.2$ mbar). Heating had to extend at least down to the 0.03 -mbar level, with the best fit extending down to 0.2 mbar. Thermal gradients and turbulence may account for this deeper but less pronounced heating than was modeled on the first day after impact. Distributions that included significant $\mathrm{NH}_{3}$ at altitudes down to and below the 3-mbar level resulted in poor fits to the line wings (e.g., Fig. 5, dotted model), and models limiting $\mathrm{NH}_{3}$ to altitudes above the 0.3 -mbar level did not fit the aQ(9,8) peak well. Some of these models were still within $1 \sigma$ of the best fit shown in Fig. 5, but the retrieved column densities for all of the acceptable models varied only by a factor of 2 , and the temperatures of the heated region varied by only a few degrees.

$G$ impact plus 18 days. The strong aQ $(2,2)$ line was the only one measured on this day, but its mere presence indicates that $\mathrm{NH}_{3}$ was still present in the stratosphere $2 \frac{1}{2}$ weeks after impact G. As shown in Fig. 6, the line is quite broad. At 18 days postimpact, it was difficult to discern features to track on, and a tracking error of $\pm 7^{\circ}$ longitude $( \pm 1.5 \mathrm{arcsec})$ was determined from the individual scans that compose this spectrum. This was taken into account by approximating the same tracking error, and ultimately the elongated beam shape, through the use of multiple beam positions in generating the model spectrum. This case in particular benefited from the beam-integration technique, as a mean viewing angle model did not fully take into account the range of rotational velocities across the elongated beam and resulted in a narrower line shape. Even with the tracking error taken into account, there is still additional broadening that can be accounted for by broadening due to higher pressure in the region probed ( $>1$ mbar). The brightness temperature requires the temperature in the region of line formation to be at least $170 \mathrm{~K}$.

The data were fit by uniformly varying the standard temperature profile. The best fits were within a few degrees of the 


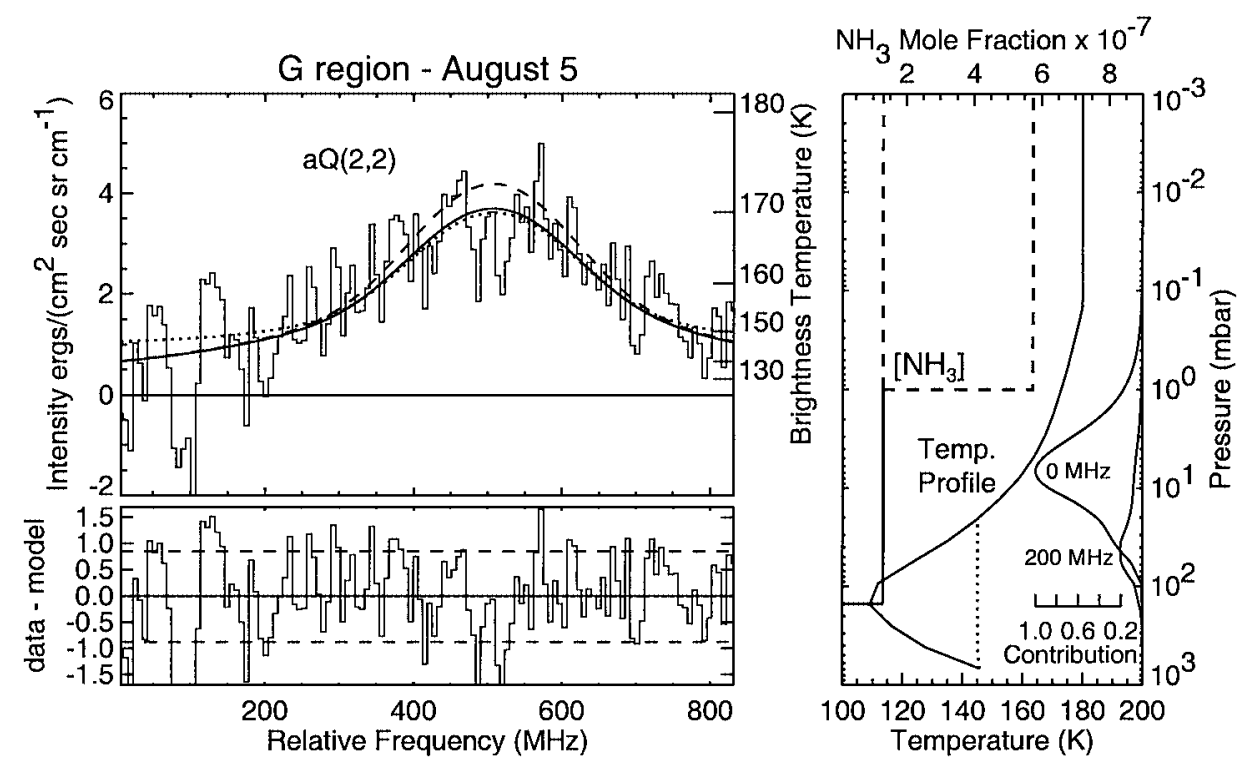

FIG. 6. G impact region spectrum from August 5, 1994 (18 days after $\mathrm{G}$ impact). The broad shape of this line indicates that the $\mathrm{NH}_{3}$ contribution is mainly from the lower stratosphere, even when tracking errors are taken into account. For a quiescent temperature profile and an $\mathrm{NH}_{3}$ distribution down to the tropopause, we retrieve a mole fraction of $(1.3 \pm 0.7) \times 10^{-7}$ (column density above $50 \mathrm{mbar}(7.3 \pm 1.7) \times 10^{17} \mathrm{~cm}^{-2}$ ). The dotted model shows the maximum amount of tropopause heating that can be tolerated by the data, and the resulting $\mathrm{NH}_{3}$ mole fraction is $1.1 \times 10^{-7}$. The dashed model includes the derived upper limit for $\mathrm{NH}_{3}$ above the 1-mbar level of $6.5 \times 10^{16} \mathrm{~cm}^{-2}$.

quiescent profile, so a quiescent profile was adopted for the final $\mathrm{NH}_{3}$ retrievals. A simple gray atmosphere radiative flux calculation (Deming and Harrington 2001) using the starting temperature suggested by the 4-day $\mathrm{G}$ observation indicates that a return to a quiescent upper stratospheric temperature by 18 days postimpact is reasonable. This is also consistent with results of Kostiuk et al. (1996), who indicated a return to near quiescent temperature $\sim 8$ days after the $\mathrm{Q} 1$ and $\mathrm{R}$ impacts, and with our results on the $\mathrm{K}$ region 7 days after impact (see below).

This spectrum acquired 18 days after impact cannot be modeled adequately using $\mathrm{NH}_{3}$ distributed only above the 1-mbar level, as with spectra from the first days after impact. The spectrum can best be modeled using $\mathrm{NH}_{3}$ distributed down to the tropopause (150 mbar). This distribution requires an $\mathrm{NH}_{3}$ mole

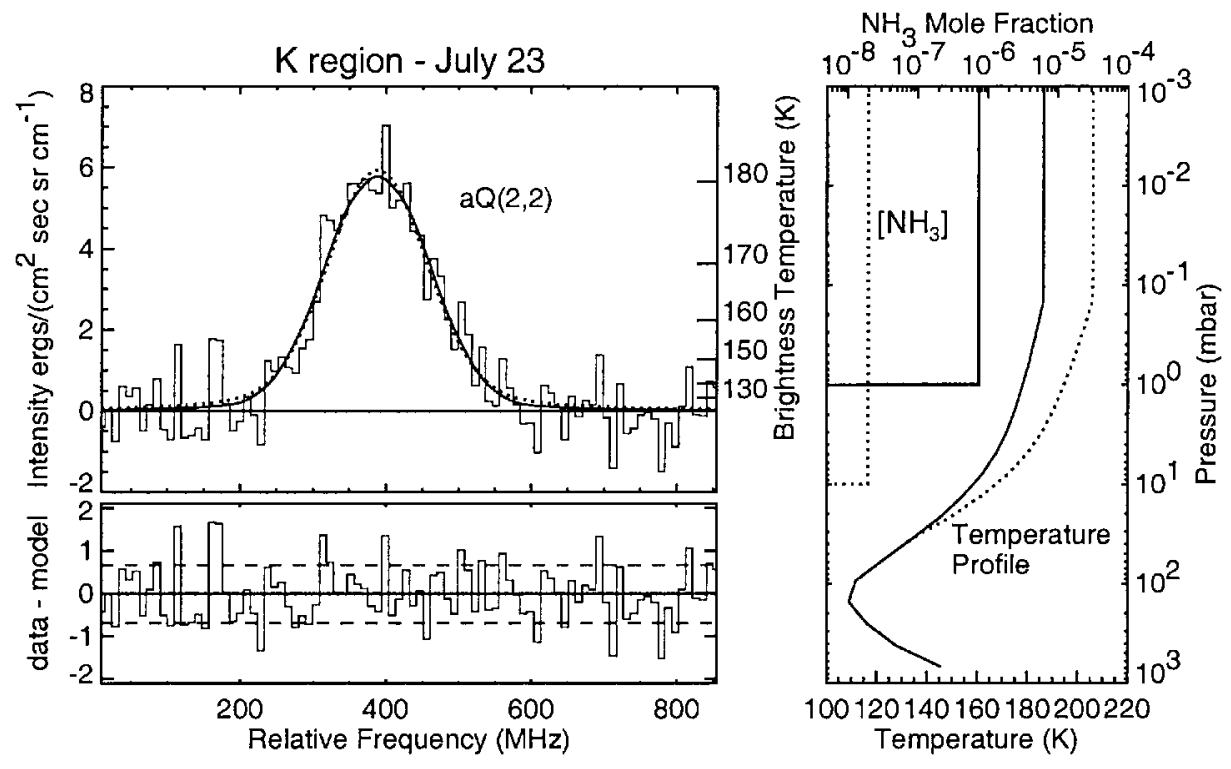

FIG. 7. K impact region spectrum from July 23, 1994 (4 days after K impact). Although more difficult to determine precisely, the temperature must be at least $187 \mathrm{~K}$ above 0.1 mbar, which results in an $\mathrm{NH}_{3}$ mole fraction of $\sim 10^{-6}$ above 1 mbar $\left(\sim 10^{17} \mathrm{~cm}^{-2}\right)$. The dotted model illustrates that a higher temperature with a corresponding difference in $\mathrm{NH}_{3}$ distribution can also provide an acceptable fit. 
fraction of $(1.3 \pm 0.3) \times 10^{-7}$ (Fig. 6). The bulk of the line center contribution is from between $\sim 2$ and $\sim 20$ mbar (Fig. 6). The half-maximum line wing contribution $(200 \mathrm{MHz}$ from line center) is from $\sim 50$ mbar. The contribution below the $\sim 50$-mbar level is not as significant. The column density above the 50-mbar level for the retrieved mole fraction is $(7.3 \pm 1.7) \times 10^{17} \mathrm{~cm}^{-2}$. This is as high as the $\mathrm{NH}_{3}$ column densities retrieved closer to the impact time above the 1-mbar level, suggesting an additional lower altitude source for the $\mathrm{NH}_{3}$. We derived an upper limit to the $\mathrm{NH}_{3}$ abundance above the 1-mbar level by varying the mole fraction distribution as shown in Fig. 6 (dashed model). An upper limit to the $\mathrm{NH}_{3}$ column density above the 1-mbar level of $6.5 \times 10^{16} \mathrm{~cm}^{-2}$ was retrieved.

\section{K Impact Region}

$K$ impact plus 4 days. Only the $\mathrm{aQ}(2,2) \mathrm{NH}_{3}$ line was measured at the $\mathrm{K}$ region 4 days after the $\mathrm{K}$ impact. Without additional lines, simultaneous $\mathrm{NH}_{3}$ abundance and temperature retrieval is less constrained. However, fits to the line did indicate that the contribution comes primarily from above the few-mbar level, and the temperature is above quiescence. The better fits to this spectrum put an $\mathrm{NH}_{3}$ mole fraction of $\sim 1.0 \times 10^{-6}$ at altitudes above $1 \mathrm{mbar}$, and a temperature in that region of $187 \mathrm{~K}$ (Fig. 7). The column density retrieved for this case is $(1.2 \pm 1.0) \times$ $10^{17} \mathrm{~cm}^{-2}$. The $187 \mathrm{~K}$ temperature represents a lower limit. As indicated in Fig. 7, other combinations of temperature and $\mathrm{NH}_{3}$ mole fraction (dotted curves) could provide acceptable fits to the single $\mathrm{NH}_{3}$ line. The column density varied by no more than a factor of 2 for all the assumed profiles.

$K$ impact plus 7 days. The $\mathrm{aQ}(2,2)$ and $\mathrm{aQ}(6,6)$ lines were both observed at the $\mathrm{K}$ impact region 1 week following the $\mathrm{K}$ impact. The retrieved temperature profiles were all within $\pm 5 \mathrm{~K}$ of quiescent values. This is consistent with other retrievals (e.g., Kostiuk et al. 1996) for a comparable period after impact, and with radiative cooling calculations (Deming and Harrington 2001). The fit to a quiescent temperature profile (Fig. 3, profile $a$ ) is shown in Fig. 8. The lineshapes put the $\mathrm{NH}_{3}$ at altitudes above

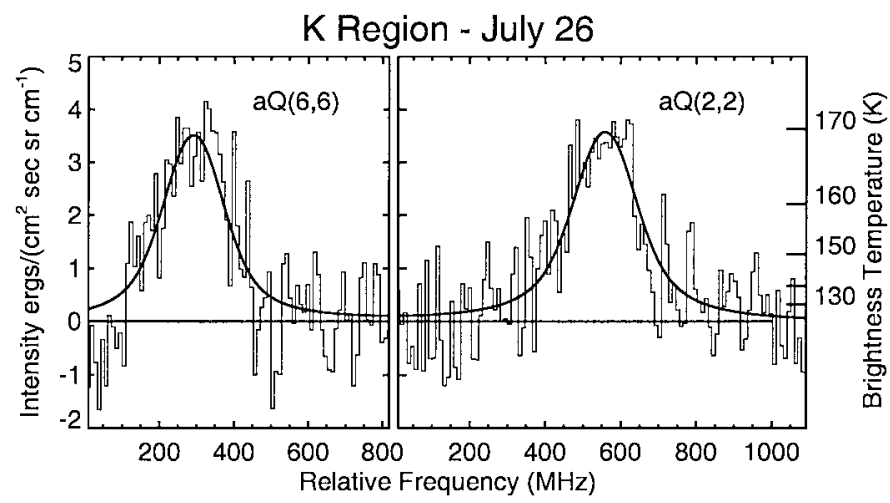

FIG. 8. K impact region spectrum from July 26, 1994 (7 days after K impact). These spectra can be fit using a quiescent profile, resulting in an $\mathrm{NH}_{3}$ mole fraction of $(8.2 \pm 1.0) \times 10^{-8}$ above 10 mbar (column density $(9.3 \pm$ 1.1) $\times 10^{16} \mathrm{~cm}^{-2}$ ).

10 mbar, with a mole fraction of $(8.2 \pm 1.0) \times 10^{-8}$ and a column density of $(9.3 \pm 1.1) \times 10^{16} \mathrm{~cm}^{-2}$.

\section{DISCUSSION}

A summary of our retrievals for the $\mathrm{G}$ and $\mathrm{K}$ impact regions can be found in Table III. These retrieved results provide insight into the processes that occurred over the 18-day period following the SL9 fragment impacts. The spectral lineshapes measured provided information on the changes in the stratospheric thermal structure and the deposited $\mathrm{NH}_{3}$ abundance and altitude distribution. This information can be used to test photochemical models of $\mathrm{NH}_{3}$ in the jovian stratosphere, their temporal behavior, and dependence on temperature.

\section{Thermal Behavior}

We found that for the $\mathrm{G}$ impact region during the first few days after the $\mathrm{G}$ impact, the spectra required high-altitude heating, which is consistent with the HD-DH plume splashback model. High-altitude heating has also been suggested by other

TABLE III

Retrieval Results Summary ${ }^{a}$

\begin{tabular}{lcccc}
\hline Impact region & UT date 1994 & Temperature & $\mathrm{NH}_{3}$ mole fraction & Column density $\left(\mathrm{cm}^{-2}\right)$ \\
\hline $\mathrm{G}+1$ day & Jul 19 & $\begin{array}{c}283 \pm 13 \mathrm{~K} \\
\text { above } 10^{-3} \mathrm{mbar}\end{array}$ & $\begin{array}{c}(6.8 \pm 1.4) \times 10^{-6} \\
\text { above } 1 \mathrm{mbar}\end{array}$ & $(7.7 \pm 1.6) \times 10^{17}$ \\
$\mathrm{G}+4$ days & Jul 22 & $\begin{array}{c}204 \pm 1 \mathrm{~K} \\
\text { above } 0.2 \mathrm{mbar}\end{array}$ & $\begin{array}{c}(3.2 \pm 0.7) \times 10^{-6} \\
\text { above } 1 \mathrm{mbar}\end{array}$ & $(3.7 \pm 0.8) \times 10^{17}$ \\
$\mathrm{G}+18$ days & Aug 5 & $\begin{array}{c}\text { Quiescent } \\
(180 \mathrm{~K})\end{array}$ & $\begin{array}{c}(1.3 \pm 0.3) \times 10^{-7} \\
\text { above } 50 \mathrm{mbar}\end{array}$ & $(7.3 \pm 1.7) \times 10^{17}$ \\
$\mathrm{~K}+4$ days & Jul 23 & $\begin{array}{c}\sim 187 \mathrm{~K} \\
\text { above } 0.1 \mathrm{mbar}\end{array}$ & $\begin{array}{c}\sim 1.0 \times 10^{-6} \\
\text { above } 1 \mathrm{mbar}\end{array}$ & $\sim 1.2 \times 10^{17}$ \\
$\mathrm{~K}+7$ days & Jul 26 & $(180 \mathrm{~K})$ & $(8.2 \pm 1.0) \times 10^{-8}$ & $(9.3 \pm 1.1) \times 10^{16}$ \\
& & above $10 \mathrm{mbar}$ &
\end{tabular}

${ }^{a}$ Uncertainties are precision of fits for the given model. See text for details. 
observations (e.g., Bézard et al. 1997). The retrieved temperature was $283 \mathrm{~K}$ above the 0.001-mbar altitude level 1 day after impact. By 4 days after impact, the retrieved temperature had cooled to $204 \mathrm{~K}$, but the heated region extended down to a few tenths of a mbar by this time.

The retrieved temperature changed by $\sim 80 \mathrm{~K}$ over 3 days. That change was much larger than what would be expected from a simple gray atmosphere radiative cooling model that only included jovian material (Deming and Harrington 2001). However, if foreign opacity (e.g., cometary water) is introduced into their cooling model, the additional opacity increases the cooling rate. In the case of water opacity, in order to reproduce the drop in temperature that was retrieved from the data, $<0.5 \%$ of the material was required to be water during that 3 -day period. Thermal emission from small silicate particles has also been found to be an efficient mechanism for cooling the atmosphere (Bézard 1997). Dynamical mixing with cool jovian air may also have contributed to the observed temperature decrease.

The retrievals from the $\mathrm{K}$ region 4 days after impact, although not as precise, are also consistent with a heated stratosphere, with temperatures greater than $187 \mathrm{~K}$. By 1 week after the K impact, the temperature appeared to have returned to a quiescent state. This is consistent with results on other impact regions (e.g., Kostiuk et al. 1996) after 1 week. We also see that by 18 days after the $\mathrm{G}$ impact, the upper stratospheric region appears to have returned to a quiescent temperature.

\section{Ammonia Abundance}

The $\mathrm{NH}_{3}$ abundance retrievals for the 1- and 4-day post$\mathrm{G}$ impact spectra indicate that the bulk of the observed $\mathrm{NH}_{3}$ contribution originated from altitudes above 1 mbar. The retrieved column densities (Table III) are consistent with other IR measurements for $\mathrm{G}$ and other large impacts such as those of Orton et al. (1995), Kostiuk et al. (1996), and Conrath (personal communication, 1995) from SpectroCam-10 observations (Nicholson et al. 1994). HST UV observations (Noll et al. 1995, Atreya et al. 1995) retrieved lower $\mathrm{NH}_{3}$ column densities, but their results and altitude distributions vary (Yelle and McGrath 1996) depending on the assumed altitude of the scattering layers. The discrepancy between UV and IR results may be due to the fact that the UV measurements concentrate on the central impact region, whereas this work is sensitive to the entire debris field from the reentered plume.

We found that by 18 days after the $G$ impact, the spectrum could be fit using a quiescent temperature profile and an $\mathrm{NH}_{3}$ distribution in the lower stratosphere. The retrieved column density is as high as those retrieved near the impact time above the 1-mbar level (Table III). The presence of this amount of $\mathrm{NH}_{3}$ at these low altitudes suggests an additional source in the lower stratosphere. Griffith et al. (1997) suggested an additional thinlayer $\mathrm{NH}_{3}$ source in the 15 - to 30 -mbar region $\left(1-3 \times 10^{17} \mathrm{~cm}^{-2}\right)$ for the $\mathrm{K}$ site $\sim 11$ days after impact for a quiescent thermal profile. For the $\mathrm{G}$ region, our lineshape does not require a thinlayer source. When we limited an $\mathrm{NH}_{3}$ distribution to the 15- to 30-mbar region, significant heating (to $\sim 170 \mathrm{~K}$ ) in that region was required in order to obtain an adequate fit to our $\mathrm{G}$ impact spectrum, retrieving a column density of $\sim 7 \times 10^{16} \mathrm{~cm}^{-2}$.

Analysis of the HST UV data by Yelle and McGrath (1996) suggests an $\mathrm{NH}_{3}$ distribution below the 5-mbar level with a column density of $1.6 \times 10^{18} \mathrm{~cm}^{-2}$ shortly after impact, comparable to our results at 18 days. We do not see evidence for this amount of $\mathrm{NH}_{3}$ in the lower stratospheric region in the first few days following the impact, but the overwhelming contribution to our spectra from the upper stratosphere due to the plume splashback heating may have masked the contribution from the much colder lower stratosphere. The 1- and 4-day spectra can statistically support (i.e., root mean square (RMS) within $1 \sigma$ of best fit) an additional $\mathrm{NH}_{3}$ mole fraction as high as $1.3 \times 10^{-8} \mathrm{~cm}^{-2}$ below the 1-mbar level. Including our retrieved 18-day $\mathrm{NH}_{3}$ mole fraction of $1.3 \times 10^{-7}$ below the 1 -mbar level in the 1-day model causes the line wings to fit quite poorly (Fig. 4, dashed model). Large amounts of $\mathrm{NH}_{3}$ could be hidden from us soon after impact if it were present only below the 20-mbar level and if the region had not been heated significantly. It is also possible that we cannot probe below the few-mbar level early on due to the presence of dust or haze at the time of our observations. This is consistent with results by Kostiuk et al. (1996) 8.5 days after impact, which permit a haze layer up to the 10-mbar level. However, much lower spectral resolution measurements by Griffith et al. (1997) do probe down to the troposphere, where they observe an $\mathrm{NH}_{3}$ absorption feature.

One possible source for the $\mathrm{NH}_{3}$ in the lower stratosphere could be transport of $\mathrm{NH}_{3}$ gas or ice crystals from the troposphere as a result of upward diffusion, dynamical mixing, and possible heating by the explosion of the impactor in or below the $\mathrm{NH}_{3}$ ice cloud. For completeness, we determined that we could still model our spectrum with a maximum tropopause temperature of $\sim 145 \mathrm{~K}$ (Fig. 6, dotted model). This is much warmer than the condensation temperature of a solar abundance of $\mathrm{NH}_{3}$ for that pressure regime, which would permit the transport of $\mathrm{NH}_{3}$ up to the lower stratosphere (Atreya et al. 1995). A tropopause temperature of $112 \mathrm{~K}$ is already above the condensation temperature for the $\mathrm{NH}_{3}$ mole fraction that we measure $\left(1.3 \times 10^{-7}\right)$. A temperature of $112 \mathrm{~K}$ represents a $3-\mathrm{K}$ increase in the tropopause temperature and is consistent with the maximum temperature increase allowed from measurements by Orton et al. (1995) and Bézard (1997) of the L impact region. Bézard (1997) finds that the increase may be due to stratospheric silicate emission, although our measurement of the $\mathrm{NH}_{3}$ lineshapes would be unaffected by the silicate emission reported.

Ice crystal transport and subsequent sublimation mainly above the tropopause would be consistent with spectra obtained by Griffith et al. (1997) from the K impact, which show only a weak absorption underlying the $\mathrm{NH}_{3}$ emission. Dynamical mixing due to increased temperatures in the upper troposphere could further enhance the $\mathrm{NH}_{3}$ abundance in the lower stratosphere.

For the given best model atmospheres, the precision of the mole fraction retrievals was $\sim 20 \%$ for each postimpact 
observation (Table III). The accuracy of the retrievals is dependent on the accuracy of the atmospheric models, the line intensities, and the measured radiance calibration. The atmospheric models were tested as described in the individual sections corresponding to the different observations. The $10 \%$ uncertainty in calibration translates into a maximum uncertainty in mole fraction for the 1-, 4-, and 18-day G impact region measurements of 20,5 , and $40 \%$, respectively.

The total mass of $\mathrm{NH}_{3}$ within our FOV is determined to be at least $5 \times 10^{12} \mathrm{~g}$. The mass of a large cometary fragment is estimated to be $\sim 10^{14} \mathrm{~g}$ (Zahnle and Mac Low 1995, Lellouch et al. 1997). Nitrogen is believed to constitute $\sim 2 \%$ of the cometary mass, and $\mathrm{NH}_{3}<0.2 \%$ (cf. Mumma et al. 1994). We retrieved at least 2.5 times more $\mathrm{NH}_{3}$ than can be supplied by nitrogen from a large cometary fragment, suggesting a primarily jovian source for the $\mathrm{NH}_{3}$.

\section{Photochemical Models}

The $\mathrm{NH}_{3}$ abundance retrievals can be used to test photochemical models. In the case of the $\mathrm{G}$ impact region, we observed $\mathrm{NH}_{3}$ mainly above the 1-mbar level 1 day after impact. By 4 days, we saw a decrease in the abundance, and by 18 days the bulk of the $\mathrm{NH}_{3}$ contribution was from below the 1-mbar level. This agrees qualitatively with photochemical models that predict preferential destruction of $\mathrm{NH}_{3}$ at high altitudes. However, quantitatively we find that the decrease in the measured $\mathrm{NH}_{3}$ column density is inconsistent with photochemical models, which predict a decrease slower than that observed.

Two simple one-dimensional photochemical models, which we describe here, were compared to our column densities retrieved from the observations spanning 18 days. The models have many elements in common. Both models step forward in time using a Runge-Kutta method, with a time step of one jovian day so that solar fluxes can be diurnally averaged. A solar zenith angle of $61^{\circ}$, applicable to the latitude of the SL9 impacts, was used in the calculations. The models compute the $\mathrm{NH}_{3}$ photodissociation rate by assuming $\mathrm{NH}_{3}$ is the only absorber in the wavelength range 160-221 nm. Opacity from other molecular absorbers (e.g., hydrocarbons, $\mathrm{CS}_{2}$ ) and dust was neglected. Thus, the photodissociation rates, and hence $\mathrm{NH}_{3}$ loss rates, are upper limits. The models also neglect the effects of mixing on the $\mathrm{NH}_{3}$ distribution because the $\mathrm{NH}_{3}$ photolysis lifetime is $\sim 3$ orders of magnitude shorter than the eddy mixing lifetime for a quiescent jovian lower stratosphere. It is shown below that this neglect of mixing, at least for the first $\sim 20$ days postimpact, is not correct. However, these chemistry-only models allow us to determine the maximum amount of $\mathrm{NH}_{3}$ loss that could be attributed to photolysis and constrain the effects of dynamics on the $\mathrm{NH}_{3}$ distribution.

The models differ in how the products of $\mathrm{NH}_{3}$ photolysis were handled. In one, it was simply assumed that every time $\mathrm{NH}_{3}$ is photolyzed, it is irreversibly lost to some other compound (maximum loss model). In the other model, a self-consistent chemistry scheme that allowed for some recycling of $\mathrm{NH}_{3}$ (stand-alone model, Table IV) was used. This model also allowed the background atmosphere to cool with time to discern any temperature effects on the photochemical scheme. The model atmospheres used in the photochemical models were the same ones derived by the analysis of the $\mathrm{NH}_{3}$ lines (Figs. 4, 5, and 7). The transitional temperature profiles were chosen by cooling the initial profiles over time according to a simple gray atmosphere cooling model (Deming and Harrington 2001).

Maximum loss model. The maximum loss model would fail to live up to its name only if there were another species that was chemically destroying $\mathrm{NH}_{3}$, perhaps catalytically or powered by absorption of solar ultraviolet radiation at wavelengths longer than what $\mathrm{NH}_{3}$ can absorb. To check this possibility, we compared the maximum loss model's predicted $\mathrm{NH}_{3}$ column abundances over time to results of a more complex photochemical model that includes oxygen and sulfur chemistry given in Moses et al. (1995). The maximum loss model does indeed predict a more rapid loss with time than does the model of Moses et al. (1995). It is interesting to note that these two models predict a similar $\mathrm{NH}_{3}$ loss from 0 to 9 days after impact. Thereafter, the model of Moses et al. (1995) predicts a much more gradual decline of $\mathrm{NH}_{3}$ with time than does the maximum loss model. The maximum loss model represents an upper limit to the $\mathrm{NH}_{3}$ loss, and it does not depend on temperature since there is no postphotolysis chemistry involved.

\section{TABLE IV}

\section{$\mathrm{NH}_{3}$ Photochemical System (Stand-Alone Model)}

\begin{tabular}{llll}
\hline $\mathrm{J} 1$ & $\mathrm{NH}_{3}+h v \rightarrow \mathrm{NH}_{2}+\mathrm{H}$ & ${ }^{a} \varphi=1.0,160 \mathrm{~nm} \leq \lambda \leq 221 \mathrm{~nm}$ & Wu et al. 1998 \\
$\mathrm{R} 1$ & $\mathrm{NH}_{3}+\mathrm{H} \rightarrow \mathrm{NH}_{2}+\mathrm{H}_{2}$ & $k_{1}=9 \times 10^{-19} \times T^{2.4} \times e^{(-4990 / T)}$ & Ko et al. 1990 \\
& & ${ }^{b} k_{2,0}=6 \times 10^{-30}$ & Gordon et al. 1971 \\
$\mathrm{R} 2$ & $\mathrm{NH}_{2}+\mathrm{H}+\mathrm{M} \rightarrow \mathrm{NH}_{3}+\mathrm{M}$ & ${ }^{b} k_{2, \infty}=2.66 \times 10^{-11}$ & Pagsberg et al. 1979 \\
$\mathrm{R} 3$ & $\mathrm{H}+\mathrm{H}+\mathrm{M} \rightarrow \mathrm{H}_{2}+\mathrm{M}$ & $k_{3}=2.7 \times 10^{-31} \times T^{-0.6}$ & Baulch et al. 1992 \\
& & ${ }^{b} k_{4,0}=1.3 \times 10^{-28}$ & Mulenko 1987 \\
$\mathrm{R} 4$ & $\mathrm{NH}_{2}+\mathrm{NH}_{2}+\mathrm{M} \rightarrow \mathrm{N}_{2} \mathrm{H}_{4}+\mathrm{M}$ & ${ }^{b} k_{4, \infty}=1.29 \times 10^{-11}$ & Patrick and Golden 1984 \\
$\mathrm{R} 5$ & $\mathrm{NH}_{2}+\mathrm{H}_{2} \rightarrow \mathrm{NH}_{3}+\mathrm{H}$ & $k_{5}=2.09 \times 10^{-12} \times e^{(-4277 / T)}$ & Demissy and Lesclaux 1980
\end{tabular}

\footnotetext{
${ }^{a} \varphi$ is the quantum yield.

${ }^{b}$ For $k_{2}$ and $k_{4}$ the overall rate constant is given by $k_{n}=k_{n, 0} k_{n, \infty}[M] /\left(k_{n, 0}[M]+k_{n, \infty}\right)$, where $[M]$ is the atmospheric number density.
} 
Stand-alone model. The amount of $\mathrm{NH}_{3}$ loss predicted by the stand-alone photochemical model depends on the atmospheric conditions. The reactions and rates for this model are given in Table IV. For pressures greater than 50 mbar, photolyzed $\mathrm{NH}_{3}$ is recycled $\sim 90 \%$ of the time. The remaining $\sim 10 \%$ of the time, $\mathrm{N}_{2} \mathrm{H}_{4}$ (hydrazine) is formed. For pressures less than 50 mbar, the fraction of $\mathrm{NH}_{3}$ recycled depends on the temperature of the model atmosphere. If the temperature is greater than $220 \mathrm{~K}$ (which our retrievals indicate 1 day after the $\mathrm{G}$ impact), then reaction $\mathrm{R} 5$ (Table IV) is an important reaction in the chemical scheme. Under these conditions, $\mathrm{NH}_{3}$ is recycled $\sim 99 \%$ of the time and is lost to $\mathrm{N}_{2} \mathrm{H}_{4}$ postphotolysis only $\sim 1 \%$ of the time. Thus, this model predicted essentially no $\mathrm{NH}_{3}$ loss via photolysis soon after impact (i.e., as long as the temperature was greater than $220 \mathrm{~K}$ ). However, once the atmosphere cools below $220 \mathrm{~K}$, recycling of $\mathrm{NH}_{3}$ via $\mathrm{R} 5$ ceases in the model, and $\sim 75 \%$ of the $\mathrm{NH}_{3}$ is recycled while $\sim 25 \%$ of it is lost to $\mathrm{N}_{2} \mathrm{H}_{4}$.

These results, however, are sensitive to the atomic hydrogen mixing ratio profile. While the models were being run and the results analyzed, it was noticed that the $\mathrm{H}$ mixing ratios from the stand-alone $\mathrm{NH}_{3}$ photochemical model were greater than those from hydrocarbon photochemical models. In addition, the chemical lifetimes for $\mathrm{H}$ in the stand-alone model were longer than those in the hydrocarbon photochemical model over much of the region of interest. We then fixed the $\mathrm{H}$ mixing ratio profile to the values in the hydrocarbon photochemical model and ran the stand-alone model. For the cooler model atmospheres, the results were dramatic, with the stand-alone $\mathrm{NH}_{3}$ photochemical model predicting the same $\mathrm{NH}_{3}$ loss with time as the maximum $\mathrm{NH}_{3}$ loss model. The lower $\mathrm{H}$ values essentially shut down $\mathrm{R} 2$ (Table IV), and the $\mathrm{NH}_{3}$ was converted to $\mathrm{N}_{2} \mathrm{H}_{4}$ as fast as it could be photolyzed. However, for warm $(T \geq 220 \mathrm{~K})$ model atmospheres, recycling of $\mathrm{NH}_{3}$ could still be carried out by $\mathrm{R} 5$, and $\mathrm{NH}_{3}$ decay with time was intermediate to that of the maximum loss and the stand-alone $\mathrm{NH}_{3}$ photochemical models with its own $\mathrm{H}$ mixing ratio profile.

Photochemical models and $G$ impact retrievals. We compared the results of the maximum loss model to our $\mathrm{NH}_{3}$ column density retrievals for the $\mathrm{G}$ impact. The maximum loss model gives an upper limit to the $\mathrm{NH}_{3}$ loss. Since the first observation was at 1 day postimpact, the model was initialized with enough $\mathrm{NH}_{3}$ above 1 mbar at time zero that the retrieved values (maximum, nominal, and minimum based on the retrieval and $1 \sigma$ precision) were reproduced 1 day later. The model was then allowed to step forward in time to 4 days and the results $\left(\mathrm{NH}_{3}\right.$ column above 1 mbar) were compared to the retrieved values as shown in Fig. 9. In this optically thick situation, the $\mathrm{NH}_{3}$ loss rate does not depend on the initial column density. What is readily apparent is that the $\mathrm{NH}_{3}$ photochemical model, which is the maximum loss model, cannot explain the decrease in the observed $\mathrm{NH}_{3}$ column. Over this 3-day period, the maximum photochemical loss model loses a total of $7 \times 10^{16} \mathrm{NH}_{3}$ molecules $\mathrm{cm}^{-2}$, which is a loss rate (flux) of $-2.7 \times 10^{11} \mathrm{NH}_{3}$ molecules $\mathrm{cm}^{-2}$ $\mathrm{s}^{-1}$. In comparison, the retrievals from the observations require

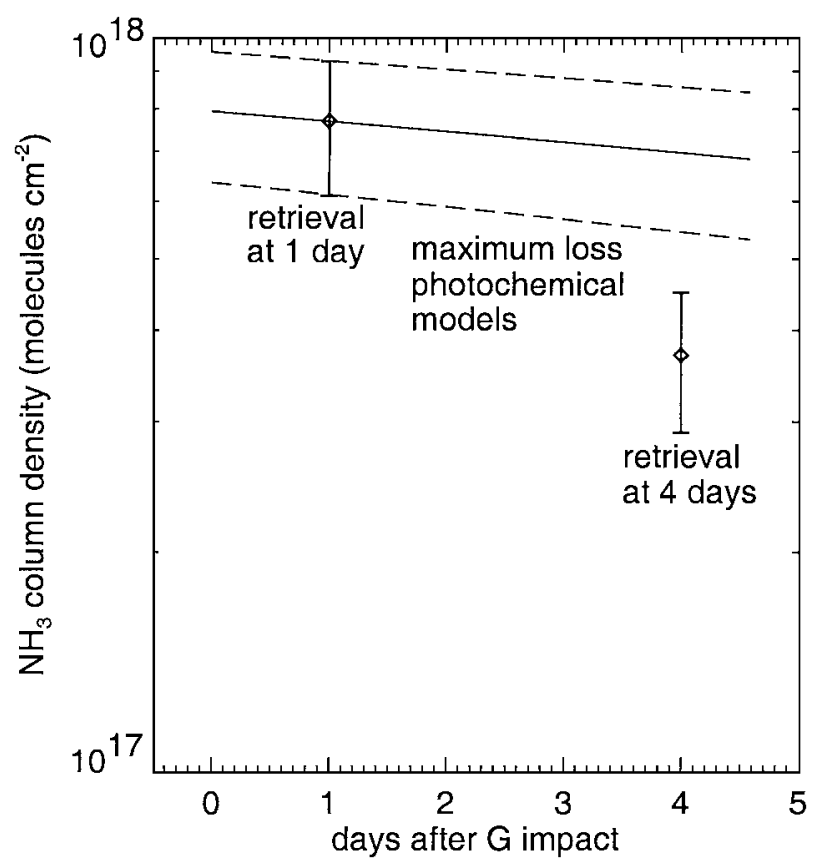

FIG. 9. Solid vertical bars represent the range in derived $\mathrm{NH}_{3}$ column density above the 1-mbar level at 1 and 4 days after the $\mathrm{G}$ impact. The curves are the $\mathrm{NH}_{3}$ column density above 1 mbar as a function of time calculated by the maximum $\mathrm{NH}_{3}$ loss photochemical model. The initial $\mathrm{NH}_{3}$ values in the photochemical models were set to reproduce the retrieved values at 1 day. The solid curve is the model based on the nominal 1-day retrieval, and the dashed curves are the models based on the upper and lower limits of the retrieval.

a total loss of $(4.0 \pm 2.4) \times 10^{17} \mathrm{NH}_{3}$ molecules $\mathrm{cm}^{-2}$, or a loss rate (flux) of $-1.5_{-0.9}^{+1.0} \times 10^{12} \mathrm{NH}_{3}$ molecules $\mathrm{cm}^{-2} \mathrm{~s}^{-1}$. At best, the maximum loss model, which gives an upper limit to the loss, can account for $\sim 40 \%$ of the $\mathrm{NH}_{3}$ loss required by the retrievals. Also, the stand-alone model, which is a more realistic model, loses $\mathrm{NH}_{3}$ at an even slower rate. Clearly, during the first 4 days after the $\mathrm{G}$ impact, impact and atmospheric dynamics dominate over photochemistry. The derived value of $\mathrm{K}$, the eddy diffusion coefficient, that supports a removal mechanism through downward flux (and condensation in lower, cooler regions) is greater than $10^{7} \mathrm{~cm}^{-2} \mathrm{~s}^{-1}$, i.e., is three orders of magnitude greater than the quiescent value. Ammonia would have to diffuse down half of a scale height over 3 days to remove enough from above the 1-mbar level, and we did not observe that. Therefore, downward diffusion of the $\mathrm{NH}_{3}$ does not appear to be the dominant removal mechanism. The combined effect of spreading, mixing with $\mathrm{NH}_{3}$-free jovian air, and photolysis may account for the observed decrease in our retrieved column density. Assuming that the drop in column density at altitudes above 1 mbar over the 3 days is due to uniform horizontal spreading alone, the inferred radial spreading velocities range from 3 to $12 \mathrm{~m} / \mathrm{s}$. This is consistent with spreading velocities obtained by Hammel et al. (1995), who retrieved velocities from 0 to $40 \mathrm{~m} / \mathrm{s}$ from other impact regions using Hubble Space Telescope WFPC2 images. The velocities depend on the position relative to the site of impact and the altitude region probed (velocities decrease with altitude). 


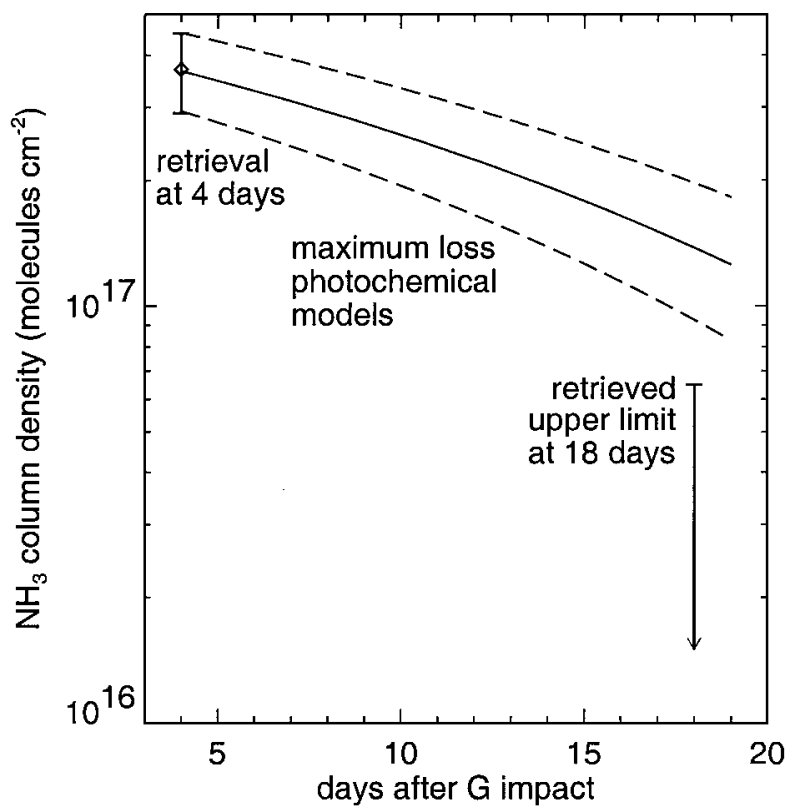

FIG. 10. Solid vertical line at 4 days represents the range in derived $\mathrm{NH}_{3}$ column density above the 1-mbar level 4 days after the $\mathrm{G}$ impact. The derived upper limit at 18 days is shown. The curves are the $\mathrm{NH}_{3}$ column density above 1 mbar as a function of time calculated by the maximum $\mathrm{NH}_{3}$ loss photochemical model. The model was initialized with the observed range in $\mathrm{NH}_{3}$ at 4 days postimpact and stepped forward in time 14 days. The solid curve is the model based on the nominal 4-day retrieval, and the dashed curves are the models based on the upper and lower limits of the retrieval.

Since the maximum loss $\mathrm{NH}_{3}$ photochemical model failed to reproduce the 4-day postimpact retrievals when started at 0 days, we reinitialized the model before analyzing the time period between 4 and 18 days postimpact. The model was started with the observed 4-day postimpact $\mathrm{NH}_{3}$ distribution and was allowed to step forward in time 14 days (to 18 days postimpact). A comparison of the photochemically derived $\mathrm{NH}_{3}$ loss to our retrieved 18-day upper limit above the 1-mbar level of $6.5 \times$ $10^{16} \mathrm{~cm}^{-2}$ is shown in Fig. 10. Once again, even the maximum loss model cannot reproduce the observed decrease in the $\mathrm{NH}_{3}$ column. However, photochemical loss is becoming more important. Since this is no longer an optically thick situation, the $\mathrm{NH}_{3}$ loss rate depends on the amount of $\mathrm{NH}_{3}$ present. The model that is initialized with the lower limit column density of $2.9 \times 10^{17} \mathrm{NH}_{3}$ molecules $\mathrm{cm}^{-2}$ loses $2.0 \times 10^{17} \mathrm{NH}_{3}$ molecules $\mathrm{cm}^{-2}$ over the 14-day period, resulting in a loss rate (flux) of $-1.6 \times 10^{11} \mathrm{NH}_{3}$ molecules $\mathrm{cm}^{-2} \mathrm{~s}^{-1}$. In comparison, the observations require a total loss of $2.2 \times 10^{17} \mathrm{NH}_{3}$ molecules $\mathrm{cm}^{-2}$, or a loss rate (flux) of $-1.9 \times 10^{11} \mathrm{NH}_{3}$ molecules $\mathrm{cm}^{-2}$ $\mathrm{s}^{-1}$ for this extreme case (minimum $\mathrm{NH}_{3}$ loss supported by the observations). The maximum loss model can account for up to $\sim 90 \%$ of the observed $\mathrm{NH}_{3}$ loss. However, it should be noted again that any more realistic model that includes such things as recycling of $\mathrm{NH}_{3}$ postphotolysis (e.g., the stand-alone model) or UV shielding of $\mathrm{NH}_{3}$ by dust and other absorbers would only have a slower rate of $\mathrm{NH}_{3}$ loss.
We find photochemistry to be too slow/inefficient to account for the retrieved decay of $\mathrm{NH}_{3}$ column density above the 1-mbar level over the first 18 days postimpact. The opposite was concluded by Griffith et al. (1997) for the K impact region. They retrieved an $\mathrm{NH}_{3}$ column density of $(0.5-2) \times 10^{16} \mathrm{~cm}^{-2}$ above the $\sim 0.1$-mbar level $21 \mathrm{~h}$ after impact, and the same results at 6 days postimpact with the decrease in $\mathrm{NH}_{3}$ emission attributed to stratospheric cooling. At 11-12 days postimpact, they could place only upper limits of $10^{14} \mathrm{~cm}^{-2}$ above the 0.1 -mbar level and $3 \times 10^{15} \mathrm{~cm}^{-2}$ above the 5-mbar level. They compared these retrievals with the $\mathrm{NH}_{3}$ photochemical loss rates of $3 \times 10^{16} \mathrm{~cm}^{-2}$ over 3 days and $8 \times 10^{16} \mathrm{~cm}^{-2}$ over 9 days from Moses et al. (1995). Griffith et al. (1997) concluded that the $\mathrm{NH}_{3}$ must have been shielded from photolysis by either dust or another molecular absorber in the UV to explain the presence of $\mathrm{NH}_{3}$ above the 1-mbar level 6 days postimpact. They found that the virtual disappearance of $\mathrm{NH}_{3}$ from above the 5-mbar level by 11-12 days postimpact could be adequately explained by the Moses et al. (1995) loss rates. However, those loss rates were based on higher column densities, $\sim 10^{17} \mathrm{~cm}^{-2}$. This is important because the $\mathrm{NH}_{3}$ destruction rate due to photolysis is proportional to the amount of $\mathrm{NH}_{3}$ present. Applying those loss rates to the Griffith et al. derived $\mathrm{NH}_{3}$ column densities overestimates the $\mathrm{NH}_{3}$ photolysis loss.

To investigate this further, we used our maximum loss rate model to analyze the K impact retrievals of Griffith et al. (Note that this model is consistent with Moses et al. (1995); i.e., it either reproduces or overestimates the Moses et al. $\mathrm{NH}_{3}$ decay with time when started with the same initial $\mathrm{NH}_{3}$ column density.) In all cases, we assumed that the initial $\mathrm{NH}_{3}$ mole fraction was constant with height for all pressures less than 1 mbar. It is only if we initialize the model with the lower bound of $\mathrm{NH}_{3}$ column density observed at $21 \mathrm{~h}$ postimpact, that we can produce an $\mathrm{NH}_{3}$ column at 11-12 days lower than the Griffith et al. upper limits. Specifically, to allow the model-predicted $\mathrm{NH}_{3}$ to be less than their upper limits for $p<0.1$ mbar and $p<5$ mbar at $11-$ 12 days, the initial $\mathrm{NH}_{3}$ column must be $\leq 6 \times 10^{14} \mathrm{~cm}^{-2}$ for $p \leq 0.1$ mbar and $\leq 2 \times 10^{16} \mathrm{~cm}^{-2}$ for $p \leq 5$ mbar. But this is the maximum possible photolytic loss, representing an upper limit to the loss. Shielding and postphotolysis recycling of $\mathrm{NH}_{3}$ are not allowed in the model.

We propose instead the following possible interpretation of the K impact retrievals of Griffith et al. (1997). While the 21-h and 6-day postimpact retrievals do not require a decrease in the $\mathrm{NH}_{3}$ column above 1 mbar, they do allow a decrease similar to the one seen in our $\mathrm{G}$ impact retrievals over 4 days ( $\sim 50 \%)$, which we ascribe to dynamics. While the maximum $\mathrm{NH}_{3}$ loss model can produce this permitted decline in the $\mathrm{NH}_{3}$ column abundance, we do not consider it likely, because UV shielding by dust or another molecule and increased $\mathrm{NH}_{3}$ recycling in the hot stratosphere via R5 likely caused the model to overestimate the $\mathrm{NH}_{3}$ loss rate. Thus, over the first $\sim 14$ days postimpact, for both $\mathrm{G}$ and $\mathrm{K}$ impact sites, dynamical mixing with $\mathrm{NH}_{3}$-free jovian air appears to dominate over 
photochemical destruction in the observed decrease in the $\mathrm{NH}_{3}$ column.

\section{CONCLUSIONS}

We found significant heating of the upper stratosphere in the days after the impacts as a result of the plume splashback (204$283 \mathrm{~K})$. Return to a quiescent temperature takes place in about 1 week. The rate of cooling observed indicates that opacity equivalent to $<0.5 \%$ water was present in the $\mathrm{G}$ region between 1 and 4 days postimpact.

In the first days after the $\mathrm{G}$ impact, the observed $\mathrm{NH}_{3}$ appears to be primarily from plume material injected into the upper stratosphere at altitudes above 1 mbar. The retrieved $\mathrm{NH}_{3}$ mass in our FOV is at least 25 times greater than what would be expected from a large cometary fragment. This points to a jovian source for the bulk of the $\mathrm{NH}_{3}$ observed. The drop in $\mathrm{NH}_{3}$ column density between 1 and 4 days postimpact $\left(7.7 \times 10^{17}\right.$ to $3.7 \times 10^{17} \mathrm{~cm}^{-2}$ ) cannot be explained by photolysis alone. At most, photochemical destruction of $\mathrm{NH}_{3}$ can account for $\sim 40 \%$ of the observed decrease (maximum loss model). The region in the jovian stratosphere where $\mathrm{NH}_{3}$ was present, and hence where $\mathrm{NH}_{3}$ photolysis was occurring, was warm $(T>220 \mathrm{~K})$ at the time. Under those conditions, $\mathrm{NH}_{3}$ is efficiently recycled and the maximum loss model grossly overestimates the $\mathrm{NH}_{3}$ photochemical loss rate. It is likely that a combination of mixing with $\mathrm{NH}_{3}$-free jovian air, horizontal spreading of the plume material, and photolysis could account for the changes in $\mathrm{NH}_{3}$ abundance.

Eighteen days after the $\mathrm{G}$ impact, we find a high total $\mathrm{NH}_{3}$ column abundance of $(7.3 \pm 1.7) \times 10^{17} \mathrm{~cm}^{-2}$, with the bulk of the $\mathrm{NH}_{3}$ contribution coming from altitudes well below 1 mbar. The upper limit on $\mathrm{NH}_{3}$ column density 18 days after impact above the 1 -mbar level is $6.5 \times 10^{16} \mathrm{~cm}^{-2}$. This suggests a second source for $\mathrm{NH}_{3}$ at the higher atmospheric pressures, possibly upwelling from Jupiter's troposphere around a heated and turbulent central impact region, which may have been initially masked by dust and haze. The time period between 4 and 18 days postimpact appears to be a period of transition in importance between horizontal spreading and the photochemical loss of $\mathrm{NH}_{3}$. The maximum loss $\mathrm{NH}_{3}$ photochemical model can account for up to $\sim 90 \%$ of the observed $\mathrm{NH}_{3}$ loss. This simple model may be more applicable by 18 days postimpact, as the jovian stratosphere has cooled down to the point where recycling of $\mathrm{NH}_{3}$ after photolysis is less efficient. Also, if the atomic hydrogen number densities are lowered by reactions with other species, then $\mathrm{NH}_{3}$ recycling becomes very inefficient. Even so, we are overestimating the importance of $\mathrm{NH}_{3}$ photolytic loss, as the column density we used above the 1-mbar level is an upper limit.

The SL9 event provided a unique opportunity to study the photochemistry and residence time of $\mathrm{NH}_{3}$ in the stratosphere of Jupiter, where it is not normally present. These results emphasize the importance of high-resolution infrared measurements of multiple spectral features over extended periods as probes of the temporal variability of stratospheric temperature and abundance distributions of $\mathrm{NH}_{3}$ injected into the jovian stratosphere.

\section{ACKNOWLEDGMENTS}

The authors thank Drake Deming for informative discussions and suggestions. The University of Colorado authors thank Prof. C. H. Townes for the use of the Infrared Spatial Interferometer (ISI) facility on Mt. Wilson for these observations. This work was supported by the NASA Planetary Astronomy and Planetary Atmospheres Programs. Work at University of Colorado was supported by NASA Grant NAGW-3196, and the University of California ISI facility was supported by ONR Grant N00014-89-J-1583 and NSF Grants AST-9016474, AST-9119317, and AST-9321289.

\section{REFERENCES}

Atreya, S. K., S. G. Edgington, L. M. Trafton, J. J. Caldwell, K. S. Noll, and H. A. Weaver 1995. Abundances of ammonia and carbon disulfide in the jovian stratosphere following the impact of Comet Shoemaker-Levy 9. Geophys. Res. Lett. 22, 1625-1628.

Baulch, D. L., C. J. Cobos, R. A. Cox, C. Esser, P. Frank, Th. Just, J. A. Kerr, M. J. Pilling, J. Troe, R. W. Walker, and J. Warnatz 1992. Evaluated kinetic data for combustion modelling. J. Phys. Chem. Ref. Data 21, 411.

Betz, A. L., E. C. Sutton, and R. A. McLaren 1977. Infrared heterodyne spectroscopy in astronomy. In Laser Spectroscopy III (J. L. Hall and J. L. Carlsten, Eds.), Springer Series in Optical Sciences, Vol. 7, pp. 31-38. Springer-Verlag, Berlin/Heidelberg/New York.

Betz, A., R. Boreiko, M. Bester, W. C. Danchi, and D. Hale 1994. Stratospheric ammonia in Jupiter as a result of Comet SL-9. In Abstracts for Special Sessions on Comet Shoemaker-Levy 9, The 26th Meeting of the Division for Planetary Sciences, Washington DC, 31 Oct.-4 Nov. 1994, p. 25.

Bézard, B. 1997. Long-term response of Jupiter's thermal structure to the SL9 impacts. Planet. Space Sci. 45, 1251-1270.

Bézard, B., C. A. Griffith, D. Kelly, J. Lacy, T. Greathouse, and G. Orton 1997. Thermal infrared imaging spectroscopy of Shoemaker-Levy 9 impact sites: Temperatures and HCN retrievals. Icarus 125, 94-120.

Deming, D., and J. Harrington 2001. Models of the SL9 impacts. II. Radiativehydrodynamic modeling of the plume splashback. Astrophys. J. 561, 468-480.

Demissy, M., and R. Lesclaux 1980. Kinetics of hydrogen abstraction by $\mathrm{NH}_{2}$ radicals from alkanes in the gas phase: A flash photolysis-laser resonance absorption study. J. Am. Chem. Soc. 102, 2897.

Goldstein, J. J. 1989. Ph.D. thesis, University of Pennsylvania, Philadelphia.

Gordon, S., W. Mulac, and P. Nangia 1971. Pulse radiolysis of ammonia gas. II. Rate of disappearance of the $\mathrm{NH}_{2}\left(\mathrm{X}_{\mathrm{B} 1}^{2}\right)$ radical. J. Phys. Chem. 75, 2087.

Griffith, C. A., B. Bézard, T. K. Greathouse, D. M. Kelly, J. H. Lacy, and K. S. Noll 1997. Thermal infrared imaging spectroscopy of ShoemakerLevy 9 impact sites: Spatial and vertical distributions of $\mathrm{NH}_{3}, \mathrm{C}_{2} \mathrm{H}_{4}$, and 10- $\mu \mathrm{m}$ dust emission. Icarus 128, 275-293.

Hale, D. D. S., M. Besler, W. C. Danchi, W. Fitelson, S. Hoss, E. A. Lipman, J. D. Monnier, P. G. Tuthill, and C. H. Townes 2000. The Berkeley Infrared Spatial Interferometer: A heterodyne stellar interferometer for the midinfrared. Astrophys. J. 537, 998-1012.

Hammel, H. B., and 16 colleagues 1995 . HST imaging of atmospheric phenomena created by the impact of Comet Shoemaker-Levy 9. Science 267, 12881296.

Harrington, J., and D. Deming 2001. Models of the SL9 impacts. I. Ballistic Monte-Carlo plume. Astrophys. J. 561, 455-467.

Jessup, K. L., J. T. Clarke, G. E. Ballester, and H. B. Hammel 2000. Ballistic reconstruction of HST observations of ejecta motion following ShoemakerLevy 9 impacts into Jupiter. Icarus 146, 19-42. 
Ko, T., P. Marshall, and A. Fontijn 1990. Rate coefficients for the $\mathrm{H}+\mathrm{NH}_{3}$ reaction over a wide temperature range. J. Phys. Chem. 94, 1401.

Kostiuk, T. 1994. Physics and chemistry of upper atmospheres of planets from infrared observations. Infrared Phys. Technol. 35, 243-266.

Kostiuk, T., F. Espenak, M. J. Mumma, D. Deming, and D. Zipoy 1987. Variability of ethane on Jupiter. Icarus 72, 394-410.

Kostiuk, T., D. Buhl, F. Espenak, P. Romani, G. Bjoraker, K. Fast, T. Livengood, and D. Zipoy 1996. Stratospheric ammonia on Jupiter after the SL9 collision. Icarus 121, 431-441.

Kostiuk, T., K. Fast, T. A. Livengood, J. Goldstein, T. Hewagama, D. Buhl, F. Espenak, and K. H. Ro 1997. Ethane abundance on Titan. Planet. Space Sci. 45, 931-939.

Lellouch, E., B. Bézard, R. Moreno, D. Bockelée-Morvan, P. Colom, J. Crovisier, M. Festou, D. Gautier, A. Marten, and G. Paubert 1997. Carbon monoxide in Jupiter after the impact of Comet Shoemaker-Levy 9. Planet. Space Sci. 45, 1203-1212.

Margolis, J., and R. Poynter 1991. Low temperature hydrogen broadened linewidths of ammonia in the $(0,1,0,0)-(0,0,0,0)$ band. Appl. Opt. 30, 30233028 .

Moses, J. I., M. Allen, and G. R. Gladstone 1995. Nitrogen and oxygen photochemistry following SL9. Geophys. Res. Lett. 22, 1601-1604.

Mulenko, S. A. 1987. The application of an intracavity laser spectroscopy method for elementary processes study in gas-phase reactions. Rev. Roum. Phys. 32, 173.

Mumma, M. J., P. R. Weissman, and S. A. Stern 1994. Comets and the origin of the Solar System: Reading the Rosetta Stone. In Protostars and Planets III (E. H. Levy and J. I. Lunine, Eds.), p. 1177. Univ. of Arizona Press, Tucson.

Nicholson, P., and 13 colleagues 1994. Principal results from Palomar observations of the Shoemaker-Levy 9 impacts. In Abstracts for Special Sessions on Comet Shoemaker-Levy 9, The 26th Meeting of the Division for Planetary Sciences, Washington, DC, 31 Oct.-4 Nov. 1994, p. 20.

Noll, K. S., M. A. McGrath, L. M. Trafton, S. K. Atreya, J. J. Caldwell, H. A. Weaver, R. V. Yelle, C. Barnet, and S. Edgington 1995. HST spectroscopic observations of Jupiter after the collision of Comet Shoemaker-Levy 9. Science 267, 1307-1313.

Orton, G., and 57 colleagues 1995. Collision of Comet Shoemaker-Levy 9 with Jupiter observed by the NASA infrared Telescope Facility. Science 267, 1277-1288.

Pagsberg, P. B., J. Eriksen, and H. C. Christensen 1979. Pulse radiolysis of gaseous ammonia-oxygen mixtures. J. Phys. Chem. 83, 582.

Patrick, R., and D. M. Golden 1984. Kinetics of the reactions of $\mathrm{NH}_{2}$ radicals with $\mathrm{O}_{3}$ and $\mathrm{O}_{2}$. J. Phys. Chem. 88, 491 .

Rothman, L. S., R. R. Gamache, R. H. Tipping, C. P. Rinsland, M. A. H. Smith, D. C. Benner, V. M. Devi, J.-M. Flaud, C. Camy-Peyret, A. Perrin, A. Goldman, S. T. Massie, L. R. Brown, and R. A. Toth 1992. The HITRAN molecular database: Editions of 1991 and 1992. J. Quant. Spectrosc. Radiat. Transfer 48, 469-507.

Wu, C. Y. R., F. Z. Chen, D. L. Judge, and J. Caldwell 1998. Temperaturedependent photoabsorption study of atmospheric gases with application to planetary atmospheres. In NASA Laboratory Space Science Workshop, Harvard-Smithsonian Center for Astrophysics, Conference Proceedings, pp. 262-265.

Yelle, R. V., and M. A. McGrath 1996. Ultraviolet spectroscopy of the SL9 impact sites. I. The 175-230 nm region. Icarus 119, 90-111.

Zahnle, K., and M.-M. Mac Low 1995. A simple model for the lightcurve generated by a Shoemaker-Levy 9 impact. J. Geophys. Res. Lett. 100, 16,88516,894 . 